\title{
HUBUNGAN PENGETAHUAN DAN KOMUNIKASI PERAWAT DENGAN PELAKSANAAN PERENCANAAN PULANG DI RUANG RAWAT INAP RSUD ZAINAL ABIDIN PAGARALAM WAY KANAN
}

\author{
Teguh Pribadi ${ }^{1}$, M. Ricko Gunawan ${ }^{2}$, Djunizar Djamaludin ${ }^{3}$ \\ 1Dosen Program Studi Ilmu Keperawatan Universitas Malahayati Bandar \\ Lampung. Email : teguh@malahayati.ac.id \\ ${ }^{2}$ Dosen Program Studi Ilmu Keperawatan Universitas Malahayati Bandar \\ Lampung. Email : muhrickogunawan@malahayati.ac.id \\ 30osen Program Studi IImu Keperawatan Universitas Malahayati Bandar \\ Lampung. Email : djunizardjamaludin@gmail.com
}

\section{ABSTRACT : THE RELATIONSHIP KNOWLEDGE AND NURSING COMMUNICATION WITH THE IMPLEMENTATION OF PATIENT RECOVERY PLANNING INPATIENT RSUD ZAINAL ABIDIN PAGARALAM WAY KANAN 2018}

Background: In Indonesia, as many as $(61 \%)$ nurses in Yogyakarta do not undertake home planning. In addition, research conducted in Bandung showed that as many (54\%) nurses did not carry out the planning home. In Lampung Province, especially in Zainal Abidin Pagaralam Way Kanan Hospital, based on observation of the list of outgoing patients, not all nurses write home plans for the patients. Only 32 list (25\%) of the 128 list of information have been made back home (Medical Record of RSUD Zainal Abidin Pagaralam Right Way, 2017).

Purpose: To know the relationship of knowladge and nurse communication with the implementation of planning to go home in hospital room of Zainal Abidin Pagaralam Hospital Right Way of Year 2018.

Methods: The type of this research is quantitative, the design in this study used the design of Analytic Survey with cross sectional approach, the number of population and the sample of 72 people, the sample technique in this study is the total sampling. The research will be conducted at RSUD Zainal Abidin Pagaralam Way Kanan Year 2018, with questionnaire research instrument and statistic test using chi-square test.

Results: In this research, it was found that $38(73,7 \%)$ were not good enough and $10(26,3 \%)$ were good implementation with p-value $(0,001)$ and 37 respondents had bad communication obtained $28(75,7 \%)$ the implementation is not good and $9(24,3 \%)$ the implementation is good with p-value $(0.000)$.

Conclusion: There is a Significant Relation Between Nursing Knowledge and Communication With Implementation of Planning Home in the Inpatient Room of Zainal Abidin Pagaralam Hospital Right Way of Year 2018. The suggestion in this research is to prepare in planning the making of standard policy guideline for planning the return home.

Keywords : Pediatric Communication, Implementation, Planning Home

INTISARI: HUBUNGAN PENGETAHUAN DAN KOMUNIKASI PERAWAT DENGAN PELAKSANAAN PERENCANAAN PULANG DI RUANG RAWAT INAP RSUD ZAINAL ABIDIN PAGAR ALAM WAY KANAN

Pendahuluan :Di Indonesia, sebanyak (61\%) perawat di Yogyakarta tidak melaksanakan perencanaan pulang. Selain itu, penelitian yang dilakukan di Bandung menunjukkan bahwa sebanyak (54\%) perawat tidak melaksanakan 
perencanaan pulang. Sedangkan di Provinsi Lampung khususnya RSUD Zainal Abidin Pagaralam Way Kanan, berdasarkan observasi terhadap list pasien pulang, tidak semua perawat menuliskan perencanaan pulang untuk pasien, hanya 32 list (25\%) dari 128 list yang tertera keterangan telah melakukan perencanaan pulang (Rekam Medik RSUD Zainal Abidin Pagaralam Way Kanan, 2017).

Tujuan : Untuk mengetahui hubungan pengetahuan dan komunikasi perawat dengan pelaksanaan perencanaan pulang di ruang rawat inap RSUD Zainal Abidin Pagaralam Way Kanan Tahun 2018.

Metode : Jenis penelitian ini adalah kuantitatif, rancangan dalam penelitian ini menggunakan desain Survei Analitik dengan pendekatan cross sectional, jumlah populasi dan sampel sebanyak 72 orang, teknik sampel dalam penelitian ini adalah total sampling. Penelitian akan dilakukan di RSUD Zainal Abidin Pagaralam Way Kanan Tahun 2018, dengan instrument penelitian kuisioner dan uji statistic menggunakan uji chi-square.

Hasil : Pada penelitian ini didapatkan dari 38 responden yang mempunyai pengetahun tidak baik didapatkan $28(73,7 \%)$ pelaksanaannya tidak baik dan 10 $(26,3 \%)$ pelaksanaannya baik dengan p-value $(0,001)$ dan 37 responden yang mempunyai komunikasi tidak baik didapatkan 28 (75,7\%) pelaksanaannya tidak baik dan 9 (24,3\%) pelaksanaannya baik dengan p-value $(0,000)$.

Kesimpulan : Ada Hubungan Yang Signifikan Antara Pengetahuan dan Komunikasi Perawat Dengan Pelaksanaan Perencanaan Pulang di Ruang Rawat Inap RSUD Zainal Abidin Pagaralam Way Kanan Tahun 2018. Saran dalam penelitian ini adalah mempersiapkan dalam perencanaan pembuatan pedoman standar kebijakan pelaksanaan perencanan pulang.

\section{Kata Kunci : Komunikasi Perawat, Pelaksanaan, Perencanaan Pulang}

\section{PENDAHULUAN}

Pelayanan

dikatakan berkualitas apabila pelayanan keperawatan yang diberikan sesuai dengan standar yang ditetapkan, untuk mengukur seberapa baik mutu pelayanan keperawatan yang diberikan yang diperlukan suatu indikator klinik mutu pelayanan keperawatan (Depkes, 2008; Posuma, 2013; Zainaro, 2017).

Standar pelaksanaan perencanaan pulang mengacu pada standar akreditasi rumah sakit atas ketetapan kemenkes yang menjelaskan bahwa, discharge planning harus dilakukan sebagai dasar persiapan fisik, psikologi pasien keluarga, kemandirian pasien keluarga, perawatan berkala, membantu rujukan dan meningkatkan pengetahuan serta ketrampilan keluarga dan pasien.
Standar akreditasi pelayanan rumah sakit ini dirumuskan sebagai standar APK3, yaitu kebijakan merujuk dan perencanaan pulang pasien yang telah di tuangkan pada elemen penilaian APK3. Pemulangan berdasarkan kondisi kesehatan pasien, berdasarkan kriteria pasien pulang, kesesuaian perencanaan merujuk yang berdasarkan kebutuhannya dan adanya kebijakan rumah sakit (Kementerian Kesehatan, 2012; Damawiyah \& Chasani, 2015)

Salah satu anggota tim perencana pemulangan adalah perawat, dan sebagai perencana pemulangan, perawat mengkaji setiap pasien dengan mengumpulkan dan menggunakan data yang berhubungan untuk mengidentifikasi masalah aktual dan potensial, menentukan tujuan 
dengan atau bersama pasien dan keluarga, memberikan tindakan khusus untuk mengajarkan dan mengkaji secara individu dalam mempertahankan atau memulihkan kembali kondisi pasien secara optimal dan mengevaluasi kesinambungan asuhan keperawatan Perawat bertanggung jawab untuk membuat rujukan yang sesuai dan harus mampu menentukan pengetahuan, keahlian, dan tindakan apa yang dapat membantu pasien beradaptasi terhadap lingkungan baru setelah pemulangan (Potter \& Perry, 2005; Rofi'i, Hariyanti \& Pujasari, 2013).

$$
\text { Pelaksanaan perencanaan }
$$

pulang yang diberikan secara tidak benar dapat mengakibatkan kerugian bagi pasien. Menurut Kozier (2004 )perencanaan pulang yang berjalan belum optimal dapat mengakibatkan kegagalan dalam program perencanaan perawatan pasien di rumah yang akan berpengaruh terhadap tingkat ketergantungan pasien, dan tingkat keparahan pasien saat di rumah. Hal ini didukung oleh data dari Family Care Giver Alliance (2010) yang menunjukkan bahwa akibat dari pelaksanaan discharge planning yang tidak benar, sebanyak (40\%) pasien mengalami lebih dari 65 kesalahan pengobatan setelah meninggalkan rumah sakit, dan (18\%) pasien yang dipulangkan dari rumah sakit dirawat kembali di rumah sakit dalam waktu 30 hari. Hal ini menunjukkan dampak besar dari pelaksanaan discharge planning yang tidak baik (Safrina \& Putra, 2016).

Menurut Word Health Organization (WHO) permasalahan perencanaan pulang sudah lama menjadi permasalahan dunia. Data dunia melaporkan bahwa sebanyak (23\%) perawat di Australia tidak melaksanakan discharge planning, di Inggris bagian barat daya juga menunjukkan bahwa (34\%) perawat tidak melaksanakan discharge planning (Graham, 2012; Nurjihaduddin, 2016).

Di Indonesia, sebanyak (61\%) perawat di Yogyakarta tidak melaksanakan perencanaan pulang. Selain itu, penelitian yang dilakukan di Bandung menunjukkan bahwa sebanyak (54\%) perawat tidak melaksanakan perencanaan pulang (Okatiranti, 2015). Sedangkan di Provinsi Lampung khususnya RSUD Zainal Abidin Pagaralam Way Kanan, berdasarkan observasi terhadap list pasien pulang, tidak semua perawat menuliskan perencanaan pulang untuk pasien, hanya 32 list (25\%) dari 128 list yang tertera keterangan telah melakukan perencanaan pulang (Rekam Medik RSUD Zainal Abidin Pagaralam Way Kanan, 2017).

Berdasarkan hasil penelitian Hariyati dkk (2008) yang berjudul "Evaluasi Model Perencanaan Pulang yang Berbasis Teknologi Informasi" menunjukkan bahwa ada peningkatan pengetahuan yang bermakna setelah dilaksanakan pengenalan model discharge planning yang terorganisasi terhadap pengetahuan perawat.

Penelitian yang dilakukan oleh peneliti sebelumnya yang berjudul "Pengaruh Pengetahuan Perawat Tentang Discharge Planning terhadap pelaksanaanya di RSU Dr. Pirngadi Medan Tahun 2011" yang dilakukan kepada 21 orang perawat, diperoleh 6 orang berpengetahuan baik.

Kegagalan untuk mempersiapkan pemulangan atau ketidakberhasilan pasien dan keluarganya untuk memahami pembatasan atau implikasi masalah kesehatan dapat menyebabkan terjadinya ketidaksiapan pasien dan keluarga menghadapi pemulangan, kegagalan merawat diri di rumah sehingga dapat menyebabkan 
kondisi pasien menjadi lebih buruk, meningkatkan terjadinya hambatan dan kekambuhan, serta terjadinya komplikasi yang tidak diinginkan (Perry \& Potter, 2005; Tahalel, Mulyadi, \& Hamel, 2016).

Hasil prasurvey yang dilakukan dengan wawancara pada tanggal 09Desember 2017 kepada 10 orang perawat, ketika ditanyakan tentang perencanaan pulang3 orang perawat meminta penjelasan terlebih dahulu apa yang dimaksud dengan perencanaan pulang, dan mengatakan bahwa perencanaan pulangsama dengan pendidikan kesehatan, 5 orang perawat mengetahui perencanaan pulangdan tindakan-tindakan yang dilaksanakan setelah diberitahu

\section{METODE PENELITIAN}

Jenis penelitian kuantitatif, analitik dengan pendekatan "Cross Sectional. Populasi seluruh perawat yang bertugas di rawat inap RSUD Zainal Abidin Pagaralam Way Kanan Tahun 2018, sebanyak 72 orang. bahwa perencanaan pulangsama dengan perencanaan pemulangan, namun perawat mengatakan bahwa perencanaan pulang dilaksanakan ketika pasien hendak pulang kerumah, 2 perawat lainnya tahu tentang perencanaan pulangdan tindakan-tindakan yang dilaksanakan, serta tahu kapan diberikan perencanaan pulangyaitu mulai pasien masuk sampai pasien pulang ke rumah.

Berdasarkan latar belakang, maka peneliti tertarik untuk melakukan penelitian dengan judul "Hubungan Pengetahuan dan Komunikasi Perawat Dengan Pelaksanaan perencanaan pulang Di Ruang Rawat Inap RSUD Zainal Abidin Pagaralam Way Kanan".

dengan sampel adalah 72 responden dengan pengambilan sampel secara total sampling. Data yang diambil dengan lembar kuesioner, analisis dilakukan dengan univariat (distribusi frekuensi) dan bivariat (chi-square).

\section{HASIL}

Analisa Univariat

Distribusi Frekuensi Pengetahuan Perawat Dengan Perencanaan PulangDi Ruang Rawat Inap RSUD Zainal Abidin Pagaralam Way Kanan

\begin{tabular}{lll} 
& Tabel 1 & \\
\hline Pengetahuan & Frekuensi & Persentase \\
\hline Tidak Baik & 38 & $52,8 \%$ \\
Baik & 34 & $47,2 \%$ \\
Total & 72 & $100 \%$ \\
\hline
\end{tabular}

Dari tabel 4.3 diatas, dapat dilihat jika pengetahuan perawat tentang perencanaan pulang di RSUD Zainal Abidin Pagaralam memiliki pengetahuan tidak baik 38 responden $(52,8 \%)$ dan 34 responden $(47,2 \%)$ dengan pengetahuan baik.

\section{Distribusi Frekuensi Komunikasi Perencanaan Pulang Di Ruang Rawat Inap RSUD Zainal Abidin Pagaralam Way Kanan}

Tabel 2

\begin{tabular}{lll}
\hline Komunikasi & Frekuensi & Persentase \\
\hline Tidak Baik & 37 & $51,4 \%$ \\
Baik & 35 & $48,6 \%$
\end{tabular}


Total

Dari tabel 4.4 diatas, dapat dilihat jika komunikasi perawat tentang perencanaan pulang di RSUD Zainal Abidin Pagaralam
72

$100 \%$

memiliki komunikasi tidak baik 37 responden $(51,4 \%)$ dan 35 responden $(48,6 \%)$ dengan komunikasi baik.

\section{Distribusi Frekuensi Pelaksanaan Perencanaan Pulang Di Ruang Rawat Inap RSUD Zainal Abidin Pagaralam Way Kanan}

\begin{tabular}{lll} 
& Tabel 3 & \\
\hline Pelaksanaan & Frekuensi & Persentase \\
\hline Tidak Baik & 39 & $54,2 \%$ \\
Baik & 33 & $45,8 \%$ \\
Total & $\mathbf{7 2}$ & $\mathbf{1 0 0 \%}$ \\
\hline
\end{tabular}

Berdasarkan tabel 4.4 diatas dapat dilihat jika 39 responden $(54,2 \%)$ tidak melaksanakan perencanaan pulang dengan baik,

Analisa Bivariat

Hubungan Pengetahuan Perawat Dengan Pelaksanaan Perencanaan Pulang Di Ruang Rawat Inap RSUD Zainal Abidin Pagaralam Way Kanan

Tabel 4

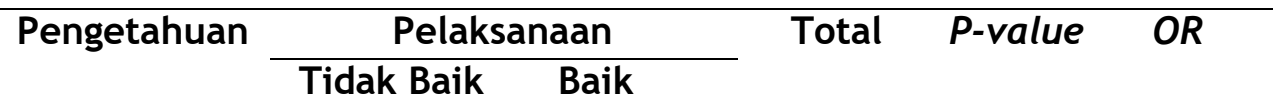

\begin{tabular}{|c|c|c|c|c|c|c|c|c|}
\hline & $\mathbf{N}$ & $\%$ & $\mathbf{N}$ & $\%$ & $\mathbf{N}$ & $\%$ & & \\
\hline Tidak baik & 28 & 73,7 & 10 & 26,3 & 38 & 100 & 0.001 & 5,855 \\
\hline Baik & 11 & 32,4 & 23 & 67,6 & 34 & 100 & & $(2,114$ \\
\hline Total & 39 & 54,2 & 33 & 45,8 & 72 & 100 & & $16,213)$ \\
\hline
\end{tabular}

Berdasarkan tabel 4.6 di atas menunjukkan dari 38 responden yang mempunyai pengetahun tidak baik didapatkan $28 \quad(73,7 \%)$ pelaksanaannya tidak baik dan 10 $(26,3 \%)$ pelaksanaannya baik. Sebanyak 34 responden yang mempunyai pengetahuan baik didapatkan $23 \quad(67,6 \%)$ pelaksanaannya baik dan 11 (32,4\%) pelaksanaannya tidak baik. Hasil uji statistic chi square didapat nilai $p$ - dan sisanya 33 responden $(45,8 \%)$ melaksanakan perencanaan pulang dengan baik. terdapat hubungan yang signifikan antara pengetahuan perawat dengan pelaksanaan perencanaan pulang di ruang rawat inap RSUD Zainal Abidin Pagaralam Way Kanan Tahun 2018, dengan nilai OR 5,855 yang artinya responden yang memiliki pengetahuan kurang baik 5,855 kali berpeluang akan tidak melaksanakan perencanaan pulang dengan baik. 


\section{Hubungan Komunikasi Perawat Dengan Pelaksanaan Perencanaan PulangDi Ruang Rawat Inap RSUD Zainal Abidin Pagaralam Way Kanan}

Tabel 5

\begin{tabular}{|c|c|c|c|c|c|c|c|c|}
\hline \multirow[t]{3}{*}{ Komunikasi } & \multicolumn{4}{|c|}{ Pelaksanaan } & \multicolumn{2}{|c|}{ Total } & \multirow[t]{3}{*}{ P-value } & \multirow[t]{3}{*}{$O R$} \\
\hline & \multicolumn{2}{|c|}{ Tidak Baik } & \multicolumn{2}{|c|}{ Baik } & \multirow[b]{2}{*}{$\mathbf{N}$} & \multirow[b]{2}{*}{$\%$} & & \\
\hline & $\mathbf{N}$ & $\%$ & $\mathbf{N}$ & $\%$ & & & & \\
\hline Tidak baik & 28 & 75,7 & 9 & 24,3 & 37 & 100 & 0.000 & 6,788 \\
\hline Baik & 11 & 31,4 & 24 & 68,6 & 35 & 100 & & $(2,409-$ \\
\hline Total & 39 & 54,2 & 35 & 45,8 & 72 & 100 & & $19,128)$ \\
\hline
\end{tabular}

Berdasarkan tabel 4.7 di atas menunjukkan dari 37 responden yang mempunyai komunikasi tidak baik didapatkan $28 \quad(75,7 \%)$ pelaksanaannya tidak baik dan 9 $(24,3 \%)$ pelaksanaannya baik. Sebanyak 35 responden yang mempunyai komunikasi baik didapatkan $24 \quad(68,6 \%)$ pelaksanaannya baik dan $11(31,4 \%)$ pelaksanaannya tidak baik. Hasil uji statistic chi square didapat nilai $p$ -

Pembahasan

Analisa Univariat

1. Distribusi Frekuensi Pengetahuan Perawat Dengan Perencanaan PulangDi Ruang Rawat Inap RSUD Zainal Abidin Pagaralam Way Kanan

Dari hasil penelitian didapatkan pengetahuan perawat tentang perencanaan pulang di RSUD Zainal Abidin Pagaralam memiliki pengetahuan tidak baik 38 responden $(52,8 \%)$ dan 34 responden $(47,2 \%)$ dengan pengetahuan baik.

Semakin rendah pendidikan seseorang maka akan menghambat perkembangan sikap seseorang terhadap penerimaan, informasi dan nilai-nilai yang baru diperkenalkannya. Sebaliknya semakin tinggi pendidikan seseorang maka semakin mudah menerima value $0.000 \quad(<0.05)$ yang artinya terdapat hubungan yang signifikan antara komunikasi perawat dengan pelaksanaan perencanaan pulangdi ruang rawat inap RSUD Zainal Abidin Pagaralam Way Kanan Tahun 2018, dengan nilai OR 6,788, artinya responden yang memiliki komunikasi kurang baik 6,788 kali berpeluang tidak melaksanakan perencanaan pulang dengan baik.

informasi, dan pada akhirnya makin banyak pula pengetahuan yang dimilikinya. Faktor internal yang mempengaruhi pengetahuan yaitu umur, dimana seseorang semakin bertambah umurnya, maka akan berkurang daya penangkapan informasinya (Backtiar, 2008; Sudiharti, 2016).

Hasil penelitian Gultom (2011), dengan sampel dalam penelitian sebanyak 21 responden menggunakan tehnik accidental sampling, hasil penelitian didapatkan 6 responden $(28,6 \%)$ berpengetahuan yang baik, sedangkan 15 responden $(71,4 \%)$ berpengetahuan yang cukup dan tidak didapatkan perawat yang berpengetahuan kurang. Hasil penelitian yang lain dari Octaviani (2015) ini menggunakan sampel sebanyak 65 responden dengan 
menggunakan proportional random sampling. Pengumpulan data dilakukan dengan cara kuesioner dan observasi, didapatkan sebanyak 25 responden

$(38,5 \%)$ berpengetahuan yang baik, sedangkan 40 responden $(61,5 \%)$ berpengetahuan yang cukup dan tidak didapatkan perawat yang berpengetahuan yang kurang. Dapat disimpulkan bahwa dari hasil penelitian dengan penelitian sebelumnya membuktikan pengetahuan perawat di ruang rawat inap Rumah Sakit Bhayangkara Palembang saat ini dapat dikatakan cukup dengan persentase $50 \%$, meskipun sebagian besar hasil masih kurang dari 75\% (Sugiharto, Keliat, \& Hariyanti, 2012).

\section{Distribusi Frekuensi Komunikasi} Perencanaan Pulang Di Ruang Rawat Inap RSUD Zainal Abidin Pagaralam Way Kanan Tahun 2018 Dari hasil penelitian didapatkan komunikasi perawat tentang perencanaan pulang di RSUD Zainal Abidin Pagaralam memiliki komunikasi tidak baik 37 responden $(51,4 \%)$ dan 35 responden $(48,6 \%)$ dengan komunikasi baik.

Komunikasi merupakan cara yang efektif untuk mempengaruhi tingkah laku manusia dan bermanfaat dalam melaksanakan pelayanan kesehatan di Rumah Sakit, sehingga komunikasi harus dikembangkan secara terus-menerus (Potter \& Perry, 2005; Suranto, 2011).

Hasil penelitian ini berbeda dengan hasil penelitian sebelumnya dengan 130 responden didapatkan yaitu dari empat fase komunikasi terapeutik perawat rata-rata adalah 55,86, semantara nilai tertinggi adalah 70 dan nilai terendah 41, hasil analisis dengan uji Spearman's rho memperoleh hasil nilai $r=0,225$ yang artinya hubungan komunikasi terapeutik perawat dengan kepuasan pasien menunjukkan hubungan yang lemah dan nilai $p=$ $0,010(<0,05)$ artinya ada hubungan antara komunikasi terapeutik perawat dengan kepuasan pasien. Peran komunikasi sebagai sarana untuk menggali kebutuhan pasien. Penelitian Darmawan (2009) dari 108 responden didapatkan hasil 59 perawat $(54,6 \%)$ yang melaksanakan komunikasi terapeutik dan 49 perawat $(45,4)$. Berdasarkan konsep dan hasil penelitian peneliti berpendapat bahwa komunikasi ini sangat penting diterapkan oleh seorang perawat karena komunikasi sangat membantu pada saat memberikan tindakan keperawatan yang profesional sehingga perlu peningkatan komunikasi dengan cara pelatihan.

\section{Distribusi Frekuensi} Pelaksanaan Perencanaan Pulang Di Ruang Rawat Inap RSUD Zainal Abidin Pagaralam Way Kanan Tahun 2018

Dari hasil penelitian didapatkan 39 responden (54,2\%) tidak melaksanakan perencanaan pulang dengan baik, dan sisanya 33 responden $(45,8 \%)$ melaksanakan perencanaan pulang dengan baik.

Perencanan pulang yang berhasil adalah suatu proses yang terpusat, terkoordinasi, dan terdiri dari berbagai disiplin ilmu yang dapat memberi kepastian bahwa klien mempunyai suatu rencana untuk memperoleh perawatan yang berkelanjutan setelah meninggalkan rumah sakit (Potter \& Perry, 2005; Yuliana,2012).

Penelitian ini berbeda dengan penelitian Octaviani (2015) dari 65 responden didapatkan hasil 42 responden $(64,6 \%)$ melaksanakan perencanan pulang dengan baik dan 23 responden $(35,4 \%)$ kurang baik. Hasil penelitian Gultom (2011) yang menggunakan sampel sebanyak 21 
responden mendapatkan 13 responden $\quad(61,9 \%) \quad$ yang melaksanakan perencanan pulang dengan baik dan 8 responden $(38,1 \%)$ tidak baik. Dapat disimpulkan dari hasil penelitian dengan penelitian sebelumnya membuktikan bahwa pelaksanaan perencanan pulang di ruang rawat inap Rumah Sakit Bhayangkara saat ini bisa dikatakan baik dengan persentase $54,2 \%$.

Hasil analisa peneliti tentang pelaksanaan perencanan pulang yang tinggi dapat ditunjukkan dari hasil penelitian berdasarkan analisa kuesioner yang diisi oleh responden terdapat pada tahap hari kepulangan pasien sehingga dipersepsikan bahwa pelaksanaan perencanan pulang yang tinggi tersebut dapat dibuktikan dengan jawaban responden yang menyatakan tidak pernah melakukan sebanyak 4 responden dan nilai tertinggi terdapat pada item yang menyatakan bahwa perawat mencatat keseluruhan format ringkasan kepulangan pasien.

\section{Analisa Bivariat}

1. Hubungan Pengetahuan Perawat Dengan Pelaksanaan Perencanaan PulangDi Ruang Rawat Inap RSUD Zainal Abidin Pagaralam Way Kanan Tahun 2018

Hasil penelitian didapatkan dari 38 responden yang mempunyai pengetahuan tidak baik didapatkan $28(73,7 \%)$ pelaksanaannya tidak baik dan $10(26,3 \%)$ pelaksanaannya baik. Sebanyak 34 responden yang mempunyai pengetahuan baik didapatkan $\quad 23 \quad(67,6 \%)$ pelaksanaannya baik dan $11(32,4 \%)$ pelaksanaannya tidak baik. Hasil uji statistic chi square didapat nilai $p$ value $0.001 \quad(<0.05)$ yang artinya terdapat hubungan yang signifikan antara pengetahuan perawat dengan pelaksanaan perencanaan pulang di ruang rawat inap RSUD Zainal Abidin Pagaralam Way Kanan Tahun 2018, dengan nilai OR 5,855 yang artinya responden yang memiliki pengetahuan kurang baik 5,855 kali berpeluang akan tidak melaksanakan perencanaan pulang dengan baik.

Menurut Pemila (2009) pengetahuan perawat tentang perencanan pulang diperlukan untuk mengkaji setiap pasien dengan mengumpulkan dan menggunakan data yang berhubungan untuk mengidentifikasi masalah aktual dan potensial, menentukan tujuan dengan atau bersama pasien dan keluarga, memberikan tindakan khusus untuk mengajarkan dan mengkaji secara individu dalam mempertahankan atau memulihkan kembali kondisi pasien secara optimal dan mengevaluasi kesinambungan Asuhan Keperawatan. Proses perencanan pulang mencakup kebutuhan fisik pasien, psikologis, sosial, budaya, dan ekonomi, dengan menyusun format discharge planning yang meliputi pengkajian, diagnosa, perencanaan, implementasi, evaluasi.Perawat mempunyai tanggung jawab utama untuk memberi instruksi kepada pasien tentang sifat masalah kesehatan, hal-hal yang harus dihindari, penggunaan obat-obatan di rumah, jenis komplikasi, dan sumber bantuan yang tersedia (Potter \& Perry, 2005; Oktaviani, 2015).

Faktor-faktor yang dapat mempengaruhi pelaksanaan perencanan pulangdiantaranya adalah motivasi, supervisi pengawasan, fasilitas, beban kerja, dan pengetahuan (Yulaita, 2011). Pengetahuan atau kognitif merupakan domain yang sangat penting untuk terbentuknya tindakan seseorang (Overt behavior), oleh karena itu 
pengalaman dan penelitian ternyata perilaku yang didasari oleh pengetahuan akan lebih langgeng daripada perilaku yang tidak didasari oleh pengetahuan (Notoatmodjo, 2007; Poglitch, Emery \& Darragh, 2011). Pengetahuan yang cukup tidak dapat menjamin perawat di Rumah Sakit Bhayangkara Palembang dapat memberikan perencanan pulang dengan baik, karena perawat mempunyai peran penting dalam perencanan pulang pasien, dimana pelaksanaannya memerlukan pengetahuan yang baik sehingga apa yang disampaikan dapat dimengerti dan berguna untuk proses perawatan dirumah (Nursalam,2009; Lelono, 2009).

Hal ini sejalan juga dengan hasil penelitian Octaviani (2015) diperoleh dari 25 perawat yang memiliki pengetahuan baik sebanyak $64 \%$ memiliki pelaksanaan baik, dan dari 40 perawat yang memiliki pengetahuan cukup sebanyak 35\% memiliki pelaksanaan buruk, hasil uji statistik didapatkan nilai $\mathrm{p}$ value $=1,000>\mathrm{p}$ value $=$ 0,005 maka dapat disimpulkan tidak ada hubungan yang signifikan antara pengetahuan perawat dengan pelaksanaan perencanan pulang. Berbeda dengan penelitian Gultom (20) didapatkan hasil penelitian dengan menggunakan analisa uji Chi square, dimana didapatkan nilai $\mathrm{p}$ value $=0,23(p<a: 0,05)$ yang bermakna bahwa ada pengaruh pengetahuan perawat tentang perencanan pulangterhadap pelaksanaannya. Hal ini didukung oleh penelitian Idayanti (2008) dimana adanya hubungan yang bermakna antara pengetahuan responden terhadap penerapan discharge planning. Dengan pengertian bahwa semakin besar kemungkinan dapat menerapkan perencanan pulang.
Menurut analisa peneliti dapat disimpulkan salah satu faktor yang dapat meningkatkan produktifitas atau kinerja perawat dalam pelaksanaan discharge planning adalah pendidikan formal perawat. Pendidikan memberikan pengetahuan bukan saja yang langsung dengan pelaksanaan tugas, tetapi juga landasan untuk mengembangkan diri serta kemampuan memanfaatkan semua sarana yang ada di sekitar kita untuk kelancaran tugas. Pengetahuan yang cukup bisa menjamin perawat di Rumah Sakit dapat memberikan discharge planning dengan baik, karena perawat mempunyai peran penting dalam discharge planning pasien, dimana pelaksanaannya memerlukan pengetahuan yang baik sehingga apa yang disampaikan dapat dimengerti dan berguna untuk proses perawatan berkelanjutan. Pada umumnya orang yang memiliki pengetahuan discharge planning baik cenderung memiliki pelaksanaan yang baik pula. Akan tetapi, tidak dipungkiri bahwa memiliki pengetahuan pelaksanaan pulang yang baik belum tentu memiliki pelaksanaan yang baik pula. Hal tersebut menurut peneliti dikarenakan pengawasan yang kurang, mengacu pada fasilitas yang ada, dan dari sikap seseorang walaupun mempunyai pendidikan yang cukup akan tetapi jika ditunjang dengan pengalaman yang baik akan menumbuhkan pelaksanaan yang positif.

2. Hubungan Komunikasi Perawat
Dengan Pelaksanaan
Perencanaan Pulang Di Ruang
Rawat Inap RSUD Zainal Abidin
Pagaralam Way Kanan Tahun
2018
Hasil penelitian didapatkan dari 37 responden yang mempunyai komunikasi tidak baik didapatkan 28 
(75,7\%) pelaksanaannya tidak baik dan $9(24,3 \%)$ pelaksanaannya baik. Sebanyak 35 responden yang mempunyai komunikasi baik didapatkan $24 \quad(68,6 \%)$ pelaksanaannya baik dan $11(31,4 \%)$ pelaksanaannya tidak baik. Hasil uji statistic chi square didapat nilai $p$ value $0.000 \quad(<0.05)$ yang artinya terdapat hubungan yang signifikan antara komunikasi perawat dengan pelaksanaan perencanaan pulangdi ruang rawat inap RSUD Zainal Abidin Pagaralam Way Kanan Tahun 2018, dengan nilai OR 6,788, artinya responden yang memiliki komunikasi kurang baik 6,788 kali berpeluang tidak melaksanakan perencanaan pulang dengan baik.

Potter dan Perry (2005) mengatakan salah satu langkahlangkah prosedur dalam perencanaan pulang yaitu perawat melakukan konsultasi dengan anggota tim kesehatan lain tentang berbagai kebutuhan pasien setelah pulang. Komunikasi sangat penting untuk proses keperawatan. Perawat menggunakan kemampuan komunikasi pada setiap langkah dari proses perawatan. Pengkajian, diagnosa keperawatan, perencanaan, implementasi, evaluasi perawatan klien bergantung pada komunikasi efektif antara perawat, klien, keluarga, dan tim perawatan kesehatan (Potter \& Perry, 2005; Mundakir, 2006).

Menentukan bagaimana teknik yang paling benar sehingga perencanan pulang dapat berkualitas dibutuhkan pembelajaran lebih mendalam untuk proses perencanan pulang. Proses ini sangat penting untuk memberikan pelayanan yang berkualitas kepada pasien. Proses tersebut menunjukkan bahwa untuk mendapatkan pelayanan yang berkualitas dibutuhkan kerjasama, perencanaan terstruktur, keamanan pasien, perawatan berkelanjutan dan dokumentasi Komunikasi yang dilakukan antar tenaga kesehatan mampu meningkatkan kedisiplinan dan kerjasama antar tim yang dapat berpengaruh pada peningkatan kualitas pelayan perencanan pulang, sehingga kerjasama tim sangat dibutuhkan dalam proses perencanan pulang (Greysen, 2012)

Berbeda dengan penelitian yang telah dilakukan oleh peneliti sebelumnya pada perawat Rumah Sakit menyatakan ada hubungan antara komunikasi dengan pelaksanaan perencanaan pulang denganp value $=0,008(p<a 0,05)$. Berdasarkan hasil penelitian serta teori yang ada maka peneliti menyimpulkan bahwa komunikasi yang diteliti oleh peneliti di Rumah Sakit Bhayangkara Palembang Tahun 2017 didapatkan tidak ada hubungan komunikasi dengan pelaksanaan perencanan pulang. Hal ini sejalan dengan penelitian yang dilakukan oleh Widiarti, Risyidi \& Widodo tentang hubungan komunikasi terapeutik perawat dengan keberhasilan pelaksanaan discharge planning pada pasien pasca pembedahan di RSUD Ungaran bahwa hasil uji statistik dengan menggunakan uji chi square didapatkan nilai x2 hitung $(5,255)>$ $x 2$ tabel $(3,84)$ dan $p$ value sebesar $0,022(a=0,05)$, maka dapat disimpulkan ada hubungan 6 komunikasi terapeutik perawat dengan keberhasilan pelaksanaan discharge planning perawat pada pasien pasca pembedahan di RSUD Ungaran (Rofi'i,Hariyanti, \& Pujasari, 2013).

Menurut analisa peneliti dapat disimpulkan dalam proses peningkatan status kesehatan upaya komunikasi kesehatan dapat memberikan kontribusi yang sangat penting dilakukan secara menyeluruh dengan melibatkan instansi terkait. Komunikasi 
kesehatan merupakan langkah dalam berkomunikasi untuk menyebarluaskan informasi kesehatan yang dapat mempengaruhi individu dan komunitas agar dapat membuat keputusan yang tepat untuk pengelolaan kesehatan. Dalam pelaksanaan discharge planning, perawat mempunyai peran utama untuk memberi instruksi kepada pasien tentang sifat masalah kesehatan, hal-hal yang harus dihindari, penggunaan obat-obatan di rumah, jenis komplikasi, dan sumber bantuan yang tersedia.

\section{KESIMPULAN}

Berdasarkan hasil penelitian dengan judul Hubungan Pengetahuan dan Komunikasi Perawat Dengan Pelaksanaan Perencanaan Pulang di Ruang Rawat Inap RSUD Zainal Abidin Pagaralam Way Kanan Tahun 2018, dapat di tarik kesimpulan :

1. Bahwa dari 72 responden di RSUD Zainal Abidin Pagaralam memiliki pengetahuan tidak baik 38 responden $(52,8 \%)$ dan 34 responden $(47,2 \%)$ dengan pengetahuan baik.

2. Bahwa dari 72 responden di RSUD Zainal Abidin Pagaralam memiliki komunikasi tidak baik 37 responden $(51,4 \%)$ dan 35 responden $(48,6 \%)$ dengan komunikasi baik.

3. Bahwa dari 72 responden di RSUD Zainal Abidin Pagaralam memiliki pelaksanaan pulang tidak baik 39 responden $(54,2 \%)$ dan 33 responden $(45,8 \%)$ dengan pelasanaan pulang baik.

4. Berdasarkan data yang diperoleh dapat dilihat bahwa hasil uji Chi square didapatkan bahwa $p$ value
0,001 , artinya lebih kecil dari alpha $(0,05)$ sehingga demikian dapat disimpulkan bahwa $\mathrm{Ha}$ diterima, ini berarti Ada Hubungan Yang Signifikan Antara Pengetahuan Perawat Dengan Pelaksanaan Perencanaan Pulang di Ruang Rawat Inap RSUD Zainal Abidin Pagaralam Way Kanan Tahun 2018.

5. Berdasarkan data yang diperoleh dapat dilihat bahwa hasil uji Chi square didapatkan bahwa $p$ value 0,000 , artinya lebih kecil dari alpha $(0,05)$ sehingga demikian dapat disimpulkan bahwa $\mathrm{Ha}$ diterima, ini berarti Ada Hubungan Yang Signifikan Antara Komunikasi Perawat Dengan Pelaksanaan Perencanaan Pulang di Ruang Rawat Inap RSUD Zainal Abidin Pagaralam Way Kanan Tahun 2018.

\section{SARAN}

\section{Bagi Rumah Sakit}

Bagi RSUD Zinal Abidin Pagaralam agar dapat mempertahankan pelaksanaan perencanan pulangdengan baik melalui :

a. Mempersiapkan dalam perencanaan pembuatan pedoman standar kebijakan pelaksanaan perencanan pulang

b. Pembentukan struktur organisasi dalam menggerakkan perencanan pulang dipimpin oleh ketua Tim dengan pembagian tugas secara Tim.

c. Meningkatkan komunikasi dan pengetahuan dari masing-masing perawat pelaksana pada pelayanan keperawatan khususnya dalam pelaksanaan 
perencanan pulang

d. Dilakukan proses evaluasi berkala untuk setiap tindakan keperawatan oleh Kepala Ruangan / Supervisor melalui supervisi dalam pelaksanaan perencanan pulang

e. Mengadakan pelatihan/Training perencanan pulang untuk perawat pelaksanaan.

f. Perlu adanya ceklist evaluasi penerapan perencanan pulang di status pasien.

\section{Bagi Universitas Malahayati} Untuk institusi pendidikan khususnya PSIK Universitas Malahayati, agar dosen dapat memasukkan dalam silabus mata kuliah kemudian di adakan praktikum khusus tentang praktek management untuk membuat perencanan pulanggseperti roleplay atau demonstrasi penerapan perencanan pulang di laboratorium sebagai bagian dari pembelajaran praktikum serta menegakkan model perencanan pulang sebagai acuan tatalaksana praktek. Memperbanyak referensi atau literatur yang berkaitan dengan pembelajaran tentang bagaimana seharusnya SOP pelaksanaan perencanan pulang dilakukan dengan baik, bagaimana berkomunikasi yang baik, lebih meningkatkan pengetahuan tentang perencanan pulang, serta sebagai acuan pembelajaran atau bahan perbandingan dalam penelitian dan penulisan skripsi

$\begin{array}{lr}\text { selanjutnya } & \text { khususnya } \\ \text { dalam pelaksanaan } & \\ \text { perencanan pulang. }\end{array}$

\section{Bagi Peneliti Lain.}

Peneliti

menyarankan agar peneliti selanjutnya dapat meneliti lebih mendalam terhadap sub-sub variabel lain dari pelaksanaan perencanan pulangbukan hanya sebatas ini tetapi cakupan yang lebih luas lagi.

\section{DAFTAR PUSTAKA}

Bahtiar, Yayan. (2012). Manajemen Keperawatan. Jakarta: Erlangga.

Budiman.,Ariyanto. (2013). Kapita Selekta Kuisioner. Jakarta: SalembaMedika.

Damawiyah, S., \& Chasani, S. (2015). Pengaruh Penerapan Discharge Planning dengan Pendekatan Family Centered Nursing Terhadap Motivasi dan Kesiapan Keluarga dalam Merawat Pasien Stroke Pasca Akut di RS. Islam Surabaya(Doctoral dissertation, Diponegoro University).

Lelono. (2009). Analisa Hubungan Komunikasi Terapeutik Perawat Dengan Tingkat Kepuasan Pasien Di Ruang Rawat Inap RSUD Liwa Lampung Barat. . Universitas Malahayati Bandar Lampung: Bandar Lampung.

\footnotetext{
Mundakir. (2006). Komunikasi Keperawatan, aplikasi dalam pelayanan. Edisi Pertama. Yogyakarta: Graha Ilmu.
} 
Notoatmodjo. (2010). Metodologi Penelitian Kesehatan. Jakarta: Penerbit PT. Rineka Cipta.

Notoatmodjo. (2012). Metodologi Penelitian Kesehatan. Jakarta: Rineka Cipta.

Nursalam,Efendi.

(2008). Pendidikan dalam

Keperawatan. Jakarta: Salemba Medika.

Nursalam. (2012). Aplikasi Metodologi Penelitian Kesehatan. Yogyakarta : Nuha Medika.

Nursalam. (2013). Manajemen Keperawatan dan Aplikasinya, Jakarta: Penerbit Salemba Medika.

Nursalam. (2017). Manajemen Keperawatan dan Aplikasinya, Jakarta: Salemba Medika.

Oktaviani. (2015). Hubungan Antara Pengetahuan Perawat Dengan Pelaksanaan Discharg Planning Di Ruang Rawat Inap Rumah Sakit Tk. II Dustira Cimahi. STIKES Aisyah: Bandung.

Poglitch., Emery., Darragh. (2011). Evaluasi Model Perencanaan Pulang yang Berbasis Teknologi Informasi Volume 12, Jakarta: Makara Kesehatan.

Nurjihaduddin, A. (2016). Hubungan Pengetahuan Perawat Pelaksana Dengan Pelaksanaan Discharge Planning Di Ruang Rawat Inap Rsud Meuraxa Banda Aceh. Universitas Unsyiah.
Posuma, C. O. (2013). Kompetensi, kompensasi, dan kepemimpinan pengaruhnya terhadap kinerja karyawan pada Rumah Sakit Ratumbuysang Manado. Jurnal EMBA: Jurnal Riset Ekonomi, Manajemen, Bisnis dan Akuntansi, 1(4).

Rhadiatul, A. S. J. (2017). Analisis Pelaksanaan Discharge Planning Dan Faktor-Faktor Determinannya Pada Perawat Di Ruang Rawat Inap Rsud Jambak Kabupaten Pasaman Barat Tahun 2017(Doctoral Dissertation, Universitas Andalas).

Rofi'i, M., Hariyati, R. T. S., \& Pujasari, H. (2013). Faktor Personil Dalam Pelaksanaan Discharge Planning Pada Perawat Rumah Sakit Di Semarang. Jurnal Manajemen Keperawatan, 1(2).

Shofiana, A. M., \& Kurniawati, T. (2014). Hubungan persepsi perawat tentang manfaat discharge planning dengan pelaksanaan discharge planning di ruang rawat inap Rumah Sakit PKU Muhammadiyah Yogyakarta (Doctoral dissertation, STIKES'Aisyiyah Yogyakarta).

Safrina, N., \& Putra, A. (2016). Persepsi Perawat Pelaksana terhadap Pentingnya Discharge Planning di Rsudza Banda Aceh. Jurnal Ilmiah Mahasiswa Fakultas Keperawatan, 1(1).

Sudiarti, D. (2016). PENINGKATAN AKTIVITAS DAN HASIL BELAJAR SISWA MELALUI MODEL PEMBELAJARAN INQUIRY 
DENGAN

MEDIA

GAMBAR. EDUCAZIONE, 4(1).

Sugiharto, A. S., Keliat, B. A., \& Hariyati, T. S. (2012). Manajemen keperawatan aplikasi MPKP di rumah sakit. Jakarta: $E G C$.

Sumah. (2014). Hubungan Pengetahuan Perawat Dengan Pelaksanaan Discharge Planning Di Rsud Dr. M. Haulussy Ambon. Universitas Kristen Maluku: Maluku.

Suranto. (2011). Komunikasi Interpersonal. Yogyakarta: Grahallmu.

Tahalele, S., Mulyadi, N., \& Hamel, R. (2016). Hubungan Antara Faktor Personil Perencanaan Pulang Dengan Kelengkapan Resume Medis Pasien Di Rumah Sakit Umum Daerah Maba Kabupaten Halmahera Timur. JURNAL KEPERAWATAN, 4(1).

Widiarti.(2012). Hubungan Komunikasi Terapeutik Perawatan Dengan Keberhasilan Pelaksanaan Discharge Plaining Pada Pasien Pasca Pembedahan di RSUD Ungaran. STIKES Ngudi Waluyo: Unggaran.

Zainaro, M. A. (2017). PENGARUH SARANA PRASARANA, PENDIDIKAN DAN MASA KERJA PERAWAT TERHADAP KEPUASAN KERJA DAN KINERJA PERAWAT DI RUANG RAWAT INAP RUMAH SAKIT UMUM DAERAH Dr. A. DADI TJOKRODIPO BANDAR LAMPUNG. HOLISTIK JURNAL KESEHATAN, 11(1), 34-41. 